\title{
Two strikes: limited NIH R55 and R56 retooling funds and abolishment of the A2 grant mechanism
}

\author{
M. Bishr Omary, ${ }^{*, \dagger, 1}$ Heather Offhaus, ${ }^{\ddagger}$ and Steven L. Kunkel ${ }^{\ddagger}, \S$ \\ *Department of Molecular and Integrative Physiology, ${ }^{\dagger}$ Department of Medicine, ${ }^{\ddagger}$ Office of \\ Research, and ${ }^{\S}$ Department of Pathology, University of Michigan Medical School, Ann Arbor, \\ Michigan, USA
}

\begin{abstract}
The U.S. National Institutes of Health (NIH) are facing significant budgetary challenges as a result of the current economic climate. The recent sunset of investigator-initiated R01-type research grants after one revised submission, coupled with the present lack of an NIH retooling funding mechanism for such grant applicants, creates a concerning risk that talented and well-trained investigators may be forced to give up their research careers. Existing NIH retooling mechanisms include the R55 Shannon Award, which was established in 1991 and was essentially replaced in 2005 by the R56 award. There is an urgent need to either significantly expand the R55/R56 mechanisms and definition of NIH grant bridging/retooling support for unfunded meritorious proposals or introduce a new mechanism that provides specific support to investigators with competitive but unfunded R01 revised grants. An expanded retooling funding mechanism deserves implementation during continuing assessment of whether allowance of only one revision of research proposals has achieved its initial intended goals.-Omary, M. B., Offhaus, H., Kunkel, S. L. Two strikes: limited NIH R55 and R56 retooling funds and abolishment of the A2 grant mechanism. FASEB J. 25, 4108-4110 (2011). www.fasebj.org
\end{abstract}

Key Words: bridge funding • research retooling

THERE ARE CURRENT MAJOR financial concerns regarding the effect of national budget constraints on research funding by the U.S. National Institutes of Health (NIH) and other federal science-related spending. The significance of these financial constraints is readily observed at the level of NIH investigator-initiated R01 extramural grants, for which success funding levels have steadily decreased to single digits across several NIH Institutes (1). Furthermore, concerns regarding the markedly declining success in funding have been compounded by the elimination of the A2 mechanism of grant reapplication (i.e., second revision of an initial R01 grant application; ref. 2), and the present lack of any well-defined NIH sponsored bridging or retooling mechanisms should the A1 first-revision application not be funded. Added to this is the recent NIH budget reduction from $\$ 31.2$ billion in 2010 to $\$ 30.9$ billion in 2011 and the projected further cuts in 2012 (3). The spending power of this budget has already been ham- pered by an average annual increase of $\sim 1.5 \%$ since 2005 that is far below the annual inflation rate. Discontinuation of the A2 mechanism as of 2009 means that grants not funded after an unsuccessful first A1 revision will no longer be considered and would have to be submitted as a new proposal that is substantially different from the last A1 version (2). This creates a major problem for those unfunded investigators, particularly those whose research program depends on a single R01.

\section{HISTORICAL PERSPECTIVE AND OVERVIEW OF THE R55 AND R56 MECHANISMS}

In prior years, the NIH used a bridging mechanism, termed the R55 Shannon Award, named after former NIH Director James A. Shannon (also called Director's Awards, a category of awards first established in 1991 by then NIH Director Bernadine Healy; ref. 4). R55 awards provide limited funds (historically $\sim \$ 100,000$ for $1 \mathrm{yr}$; Table 1 and ref. 5) to applicants of meritorious grants that did not meet the payline. The R55 mechanism has been used by NIH institutes in a very limited fashion since 2006 (Table 1). Another important retooling funding mechanism is the R56, which provides critical support for investigators who are between the initial grant submission (A0) and A1 stages. R56 support has increased since its inception in 2005, except for a decline during 2009 (Table 1) that is arguably related to funding strategies introduced under the American Recovery and Reinvestment Act (ARRA) of 2009 to target funds for meritorious projects not funded under the base appropriation. Depending on the institute, some preference is given to new investigators for the awarding of R56 grants, as is the case for the National Institute of Diabetes and Digestive and Kidney Diseases (6). A 2008 NIH announcement that described the NIH Director's Bridge Awards (NDBAs) stated:

\footnotetext{
${ }^{1}$ Correspondence: Department of Molecular and Integrative Physiology, University of Michigan Medical School, 7744 Medical Science II, 1137 E. Catherine St., Ann Arbor, MI 48109-5622, USA. E-mail: mbishr@umich.edu

doi: 10.1096/fj.11-188052
} 


\begin{tabular}{|c|c|c|c|c|c|c|c|c|}
\hline \multirow[b]{3}{*}{ Year } & \multicolumn{4}{|c|}{ Initial awards } & \multicolumn{4}{|c|}{ Total awards } \\
\hline & \multicolumn{2}{|r|}{$\mathrm{R} 55$} & \multicolumn{2}{|r|}{$\mathrm{R} 56$} & \multicolumn{2}{|r|}{$\mathrm{R} 55$} & \multicolumn{2}{|r|}{$\mathrm{R} 56$} \\
\hline & Awards & Dollars (millions) & Awards & Dollars (millions) & Awards & Dollars (millions) & Awards & Dollars (millions) \\
\hline 2001 & 14 & 1.4 & & & 14 & 1.4 & & \\
\hline 2002 & 22 & 2.2 & & & 22 & 2.2 & & \\
\hline 2003 & 14 & 1.4 & & & 14 & 1.4 & & \\
\hline 2004 & 11 & 1.1 & & & 11 & 1.1 & & \\
\hline 2005 & 8 & 0.8 & 47 & 11.7 & 9 & 0.9 & 107 & 26.1 \\
\hline 2006 & 3 & 0.3 & 54 & 15.7 & 4 & 0.4 & 113 & 28.7 \\
\hline 2007 & 5 & 0.5 & 66 & 19.9 & 5 & 0.5 & 361 & 123.1 \\
\hline 2008 & 2 & 0.2 & 87 & 29.3 & 2 & 0.2 & 419 & 137.8 \\
\hline 2009 & 2 & 0.2 & 43 & 17.5 & 2 & 0.2 & 308 & 116.9 \\
\hline 2010 & 0 & 0 & 138 & 55.8 & 0 & 0 & 234 & 91.6 \\
\hline
\end{tabular}

Data were obtained from ref. 5. Numbers do not include ARRA numbers (see ref. 8 to obtain the latter). The NIH-stated goal of the R55 is to "provide a limited award to investigators to further develop, test, and refine research techniques; perform secondary analysis of available data sets; test the feasibility of innovative and creative approaches; and conduct other discrete projects that can demonstrate their research capabilities and lend additional weight to their already meritorious applications" (17). The NIH-stated goal of the R56 is to "provide limited interim research support based on the merit of a pending R01 application while applicant gathers additional data to revise a new or competing renewal application. This grant will underwrite highly meritorious applications that if given the opportunity to revise their application could meet IC recommended standards and would be missed opportunities if not funded" (17). The discrepancy between the number of initial and total awards is probably related to the duration of some of the awards ( 1 or $2 \mathrm{yr}$ ) and whether some have no-cost extensions.

A pending, competing renewal research project grant (R01) application (original) or a resubmission application (A1, A2), which just misses the nominal funding payline for the IC to which it is primarily assigned may be nominated for the NDBA by the administering NIH Institute, provided the PI has less than $\$ 400,000$ in other support (total costs) from all sources to fund her/his research. Note that only the most meritorious A2 applications will be considered for the NDBA. Applicants may not apply for an R56 grant and applicants may not self nominate for the NDBA.

Total costs approved by the Institute or Center for the first year of the project up to $\$ 500,000$ will be provided using a one year R56 grant. (7)

In 1991, 316 R55 awards were given, distributed as follows: 196 after submissions of A0 initial grants, 91 after A1 grants, 23 after A2 grants, and 6 after A3 grants (8) (this was during the period when multiple resubmissions were allowed!). The allocation of $\$ 30$ million for the R55 program in 1991 represented $0.36 \%$ of the $\$ 8.28$ billion budget at that time (9). Notably, an analysis of the 316 funded R55 grants showed that 142 R55 awardees were able to sustain funding, based on retaining the same project number for at least $3 \mathrm{yr}(8)$. This implies a success rate of R55-supported subsequent funding of $44.9 \%$, which is far better than the reported 1991 success rates of $28.6 \%$ for R01 equivalents (R01, R23, R29, and R37; ref. 10), and indicates that such bridging support did indeed lead to high subsequent success.

To quote Dr. Healy's illuminating comment to a congressional panel: "We do not expect 1991 by any means to be a year in which we fund more than 25 or 26 percent of the applications. That is a skimpy success rate and we hope the Shannon awards will help even a little in sustaining as many as 300 to 400 scientists" (11). Now, 20 yr later, times have changed and produced payline percentiles (in contrast to the typically higher "success rates"; ref. 12) that are in the range of $8-15 \%$, with typically higher funding percentiles for new investigators (1). These percentiles are far lower now than those just a few years ago [e.g., for National Institute of Allergy and Infectious Diseases, the percentiles are 10\% (2011), 11\% (2010), 14\% (2006), and 20-22\% (19992004); ref. 13].

\section{A PROPOSED NEW RETOOLING MODEL}

If the R55/R56 mechanism continues to support meritorious applications between the A0 to A1 stage at the same proportionate level of the NIH 1991 budget, then allocation of nearly $\$ 110$ million would be needed, which is in line with the allocations made during 2009-2010 (which excludes ARRA funds), and we hope that this will continue. Our proposal deals specifically with applications that are close to but do not meet the payline after an A1 application. This is a watershed area that deserves attention, particularly for investigators who have no other R-equivalent funding or who have limited funding such as an R21.

With a very low funding percentile (even assuming success at the 15th percentile), the difference in funding merit between those grants falling in the 12th-15th and 15th-18th percentile is highly subjective. In addition, investigators with a borderline unfunded A1 application score can no longer revise their application but, instead, need to start afresh while lacking any support except for what may be provided by the investigator's institution. With a fixed pot, the obvious question is where the bridge funds will come from. One potential source is the Director's Discretionary Fund 
(DDF), which had provided the R55 Shannon and the R56 awards. In federal fiscal year 2010, the DDF was $\$ 634$ million and was used, in part, for the Director Pioneer Awards and other initiatives. Based on an assumption of the historical allocation of $\$ 100,000$ per award (which can be increased to $\$ 150,000$ ), we would project that an allocation of $\$ 50$ million $(7.9 \%$ of the 2010 DDF) would bridge 300-500 investigators on an annual basis. It may be reasonable to consider structuring the award similar to a career development award with limited indirect rates, coupled with institute ceilings on salary recovery, to maximize both the allocation and the number of investigators that could be funded from the designated pool. Because of the nature of bridging support and the opportunity for protected time to retool the necessary methods or develop additional data sets, institutions would probably be willing partners with NIH under the program.

If the NIH spends the proposed $\$ 50$ million on bridging support, this would represent only $3.4 \%$ of the $\$ 1.45$ billion that was spent by the NIH in 2010 to fund resubmitted new R01s and resubmitted continuation R01s (excluding ARRA-funded awards) (14). Furthermore, using $2010 \mathrm{NIH}$ grant data, the addition of 300 bridging awards is estimated to add $8.1 \%$ additional investigators to the 3712 investigators who were awarded R01 grants during 2010 and who do not hold any additional R01 grants (14).

With regard to the sunset of the A2, benefits such as a rise in the number of funded applications after initial submission (A0) and an increase in funding of new investigators are invoked as some of the benefits of its elimination (15). However, these benefits are yet to be proven, as the upswing in these figures started in 2009 and may be related to infusion by the ARRA or to the abolishment of the A2 mechanism, which by definition implies an increase in the number of funded A0 and A1 grants. It may still be too early to make concrete conclusions regarding the true effect of the sunset of the A2 mechanism. However, with a declining competitive funding percentile, it is hard to discount the effect it immediately has on investigators at all levels, whether they are relatively junior investigators who are attempting to renew a first NIH R01 grant or more established investigators (16). Clearly, many investigators who are affected are those whom the system has invested in for years and now may be forced to abandon research or consider relocating to other countries willing to provide them with research support. Other unintended consequences are that a harsh research funding environment is a disincentive to young talent to join the research workforce (to maintain the pipeline) and an incentive for talented established investigators (who help maintain the pipe) to consider other career options (e.g., a physician-scientist leaving research for a pure clinical practice).

We have reached a critical stage in the need for identifying bridging and retooling opportunities for investigators. The national push for scientific advancement, in tension with stagnant appropriations, low competitive success margins, and the requirement to substantially overhaul scientific direction in unsuccessful projects, has the potential to create cracks in our research workforce. A partnership between NIH and investigators' home institutions will be an important step forward to navigate this challenge. These factors lead to the conclusion that there is an urgent need to significantly expand the R55/R56 mechanism of bridging or introduce a new funding mechanism for retooling, while continuing to assess any overriding benefit from the elimination of A2 proposals. If implementation of the proposed retooling program herein is deemed by the NIH leadership to be acceptable, then specific criteria and guidelines can be promptly established with the aid of NIH intramural and extramural input.

\section{REFERENCES}

1. Rockey, S. (February 15, 2011) Paylines, percentiles and success rates. http://nexus.od.nih.gov/all/2011/02/15/paylines-percentilessuccess-rates/

2. U.S. National Institutes of Health. NIH policy on submission of resubmission (amended) applications. http:/ /grants.nih.gov/grants/ policy/amendedapps.htm

3. U.S. National Institutes of Health. NIH fiscal policy for grant awards-FY 2011 (NOT-OD-11-068). http://grants.nih.gov/grants/ guide/notice-files/NOT-OD-11-068.html

4. U.S. National Institutes of Health (June 14, 1991) NIH Guide for Grants and Contracts, Vol. 20, No. 23. http://grants.nih.gov/grants/guide/ historical/1991_06_14_Vol_20_No_23.pdf

5. U.S. National Institutes of Health. NIH Research Grants-Awards and total funding by grant mechanism, type and activity code; Table 101. http://report.nih.gov/FileLink.aspx?rid $=536$

6. U.S. National Institute of Diabetes and Digestive and Kidney Diseases Resources for new NIDDK investigators. http://www2.niddk.nih.gov/ Funding/Grants/Resources_NewInvestigators

7. U.S. National Institutes of Health. Announcing the FY 2008 NIH Director's Bridge Awards (NOT-OD-08-037). http://grants.nih.gov/ grants/guide/notice-files/NOT-OD-08-037.html

8. U.S. National Institutes of Health. Research portfolio online reporting tools (RePORT). http://projectreporter.nih.gov/reporter.cfm

9. U.S. National Institutes of Health. The NIH Almanac. http://www. nih.gov/about/almanac/appropriations/part2.htm

10. U.S. National Institutes of Health. Actual of NIH R01 equivalent success rate FY1970-2008 and estimates of NIH R01 success rates, FY 1962-1969 from CGAF. http://report.nih.gov/FileLink.aspx?rid= 796

11. Garnett, C. (June 8, 2004) Director's discretionary fund to mark 15 years. The NIH Record. http://nihrecord.od.nih.gov/newsletters/ 2004/06_08_2004/story01.htm

12. U.S. National Institutes of Health. Research project success rates by NIH institute for 2010. http://report.nih.gov/award/success/ Success_ByIC.cfm

13. U.S. National Institutes of Health. Archive of final NIAID paylines by fiscal year. http://www.niaid.nih.gov/researchfunding/paybud/ pages/paylinesfinal.aspx

14. U.S. National Institutes of Health. Research portfolio online reporting tools (RePORT); Table 210. http:/ / projectreporter.nih.gov/reporter. cfm

15. Rockey, S. (March 24, 2011) Early data on the A2 sunset. http:// nexus.od.nih.gov/all/2011/03/24/early-data-on-the-a2-sunset/

16. Fang, F. C., and Casdevall, A. (2009) NIH peer review reform-change we need, or lipstick on a pig? Infect. Immun. 77, 929-932

17. U.S. National Institutes of Health. Types of grant programs. http:// grants.nih.gov/grants/funding/funding_program.htm

Received for publication June 21, 2011. Accepted for publication September 22, 2011. 